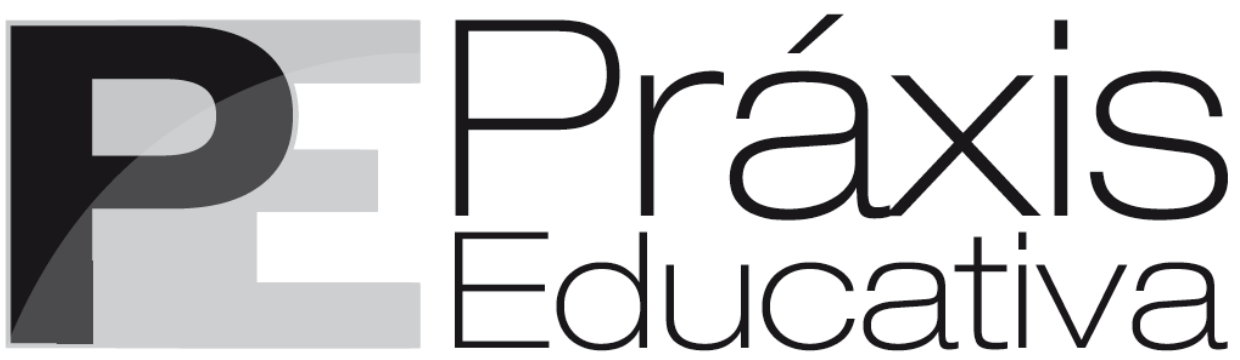

ISSN 1809-4031

elSSN 1809-4309

https://doi.org/10.5212/PraxEduc.v.15.15758.054

Documento

\title{
Declaração de voto das conselheiras representantes da Universidade Estadual de Ponta Grossa - UEPG*
}

\author{
Simone de Fátima Flach ${ }^{* *}$ \\ https://orcid.org/0000-0002-9445-0111 \\ Daiana Camargo ${ }^{* * *}$ \\ iD https://orcid.org/0000-0002-1931-5577
}

\section{Sobre a situação da Pandemia causada pelo SARS-CoV-2 e seus impactos na oferta da Educação}

Desde os meses finais do ano de 2019, o mundo foi assolado pela transmissão do coronavírus da síndrome respiratória aguda grave 2 (SARS-CoV-2). O vírus em questão é extremamente contagioso e causa a doença denominada de COVID-19, fato que fez com que diversos países se reorganizassem politicamente para conter a disseminação no âmbito mundial.

Mesmo de posse de informações a respeito das medidas necessárias para a contenção da disseminação do vírus, o Brasil não conseguiu se organizar a tempo para que a situação não colocasse em risco muitas vidas no país.

Tendo o vírus chegado ao país e sua transmissão ser local e comunitária, medidas de contenção se fizeram necessárias para tentar conter a disseminação. Estados e Municípios passaram

\footnotetext{
* O presente texto justifica voto contrário à Deliberação n ${ }^{\circ}$ 003/2020, do Conselho Municipal de Educação de Ponta Grossa, sobre Instituição de regime especial para o desenvolvimento das atividades escolares no âmbito do Sistema Municipal de Ensino de Ponta Grossa, no contexto da Pandemia causada pelo novo Coronavírus - COVID-19. A reunião para discussão da Proposta de Deliberação foi realizada na forma virtual no dia 19 de maio de 2020. A Deliberação teve 14 votos favoráveis e 3 contrários. A Deliberação no 003/2020 foi publicada no Diário Oficial do município de Ponta Grossa no dia 27 de maio de 2020, estando disponível em $<$ http:/ /www.pontagrossa.pr.gov.br/files/diario-oficial/2020-05-27-ed2844.pdf >.

** Doutora em Educação. Docente do Departamento de Educação e do Programa de Pós-Graduação da Universidade Estadual de Ponta Grossa - UEPG. E-mail: <eflach@uol.com.br>.

*** Doutora em Educação. Docente do Departamento Pedagogia da Universidade Estadual de Ponta Grossa - UEPG. E-mail: <camargo.daiana@hotmail.com>.
} 
Declaração de voto das conselheiras representantes da Universidade Estadual de Ponta Grossa...

a adotar medidas locais para promover o distanciamento social, única medida, comprovadamente, capaz de evitar a disseminação descontrolada do vírus.

Em Ponta Grossa, as medidas de distanciamento foram iniciadas pelo Decreto Municipal $\mathrm{N}^{\mathrm{o}} 17.077 / 2020$, o qual estabeleceu "[...] medidas de controle e prevenção para enfrentamento da emergência em saúde pública de decorrente do Novo Coronavírus (COVID-19)" (PONTA GROSSA, 2020, p. 4), dentre as quais a proibição de reuniões com mais de 25 pessoas. Desde então, as instituições de ensino deixaram de atender presencialmente aos estudantes matriculados em seus estabelecimentos.

Convém lembrar que, face à situação atípica, as atividades escolares foram suspensas com o intuito de retorno breve ou quando fosse possível a segurança sanitária. Alguns estabelecimentos de ensino, notadamente aqueles circunscritos à esfera privada, passaram a disponibilizar atividades pedagógicas para que os estudantes as realizassem em suas residências, sob a supervisão de pais ou responsáveis.

No que diz respeito às instituições públicas, não houve orientação unificada a respeito, ficando sob a responsabilidade e o compromisso de a comunidade escolar disponibilizar ou não alguma atividade para manter o vínculo entre escola e alunos.

Em 20 de abril de 2020, a Secretaria Municipal de Educação iniciou transmissão de aulas e/ou atividades pedagógicas por meio televisivo, sem o intuito de obrigatoriedade, mas como alternativa para manter o vínculo de alunos e de professores com o processo ensino-aprendizagem.

Alguns estabelecimentos também organizaram atividades para que os alunos realizassem em suas residências, sendo estas enviadas aos pais por meio de mídias digitais ou mensagem de WhatsApp.

É importante destacar que o município de Ponta Grossa é bastante diverso e possui inúmeras famílias em situação de vulnerabilidade social, fato que os coloca à margem do acesso às mídias digitais, à falta de recurso financeiro para promover aproximação de seus filhos e/ou pupilos ao conhecimento sistematizado sem o auxílio do poder público ou da mediação direta da escola. Apenas para ilustrar a questão, o município de Ponta Grossa, no ano de 2006, contava com 136 pontos de favelas, com 51.850 pessoas morando nesses locais, sendo, assim, o equivalente a $17,2 \%$ da população (NASCIMENTO; MATIAS, 2011).

Nos últimos anos, houve um empobrecimento da população brasileira em geral, não ficando o município de Ponta Grossa fora desse cenário. Cabe lembrar que não apenas as pessoas que vivem em favelas se encontram em situação de vulnerabilidade social e financeira, pois a crise econômica nacional afeta vários grupos sociais, fato que coloca tais sujeitos em situação precária para a oferta de condições mínimas que garantam o acesso ao conhecimento. A situação da pandemia agravou tal realidade, colocando às famílias preocupações relativas à sobrevivência material.

Por essas razões, e sem um estudo detalhado sobre a realidade em que vivem os alunos matriculados na educação pública, a aprovação de Deliberação que institui regime especial para o desenvolvimento de atividades escolares não presenciais coloca mais uma responsabilidade aos pais e/ou responsáveis, em momento tão turbulento da vida social. Mais do que aprovar medida no atropelo das discussões, seria necessário um estudo profundo e cauteloso sobre a realidade dos educandos e as possibilidades de acompanhamento pedagógico por pais, professores e demais afetos à medida. 
Além disso, há de pensar-se nos profissionais da educação que farão o acompanhamento das atividades, visto que, como seres reais, também têm apreensões, dificuldades e incertezas sobre a nova realidade criada pela Pandemia. Estão os professores munidos das ferramentas necessárias para realizar atendimento remoto, sem perder a qualidade do processo e sem perder qualquer aluno? Temos dúvidas a respeito dessas questões.

\section{Sobre a garantia do direito à Educação}

A Constituição Federal de 1988 garante a todos os brasileiros direitos iguais, inclusive os direitos sociais, dentre os quais se insere a educação. Para tanto, prevê igualdade de condições de acesso e permanência na escola, conforme inciso I do art. 206 (BRASIL, 1988), princípio reafirmado pela Lei $\mathrm{N}^{\circ}$ 9.394/96 (BRASIL, 1996). Como a permanência na escola não é possível em momento de pandemia, a igualdade de condições de acesso aos conteúdos escolares, ou atividades escolares não presenciais deve ser assegurado a todos, indistintamente. Cabe ao poder público garantir esse acesso em momento tão controverso, como o atualmente vivido.

Por isso, promover ensino remoto, ou atividades escolares não presenciais sem a devida garantia para todos, pode promover e aprofundar as desigualdades já existentes. Nesse sentido, para garantir o direito à educação a todos os alunos, há necessidade de estudo sobre a existência de tais condições e prever, dentre outras coisas, os materiais e os equipamentos necessários para o desenvolvimento de atividades escolares, mesmo que na forma não presencial. Caso isso não seja feito, o Conselho Municipal de Educação estará delegando tal responsabilidade às famílias, e as mais vulneráveis são as que mais sofrerão os efeitos de tal medida.

Por isso, reafirmamos a necessidade de estudo e de planejamento amplo sobre como ocorrerá o atendimento e a oferta das ferramentas e dos insumos necessários, principalmente aos mais vulneráveis. Nesse quesito é importante destacar que a vulnerabilidade não ocorre apenas no campo econômico, mas também no cultural e mesmo familiar. Há famílias sem condições estruturais e culturais para o acompanhamento das atividades propostas, há famílias sem acesso à energia elétrica, há famílias sem qualquer disponibilidade de comunicação para com a escola. Como garantir o direito à educação para esses sujeitos de direitos? Como ocorrerá a orientação aos pais, sem que as regras de distanciamento social sejam burladas?

Cabe ao Conselho Municipal de Educação não apenas normatizar a questão, mas analisar todas as contradições postas nessa realidade.

\section{Sobre a retroatividade proposta para o dia 23 de março}

Entendemos que a retroatividade prevista de forma ampla no Parágrafo Único do art. $1^{\circ}$ não atende à realidade, visto que há situações distintas a serem consideradas.

Instituir o regime especial precisa levar em consideração as datas em que efetivamente ocorreram planejamentos específicos de atividades não presenciais, sob o risco de criar brechas para validação de atividades não realizadas e mais uma vez, aprofundar as desigualdades.

Tendo a retroatividade sido proposta, não há necessidade de aprovação imediata da deliberação, pois esta poderia estar presente em votação futura, que levasse em consideração a realidade dos estudantes atendidos. Nesse sentido, não concordamos com a proposta de retroatividade, nesse momento posto. 
Declaração de voto das conselheiras representantes da Universidade Estadual de Ponta Grossa...

\section{Sobre atividades não presenciais para a Educação Infantil (Pré-Escola)}

A Educação Infantil, na qualidade de primeira etapa da Educação Básica, precisa ser analisada em sua especificidade, visto que os encaminhamentos pedagógicos não se circunscrevem apenas ao ensino, mas aos cuidados necessários para cada faixa etária.

O atendimento educacional na Educação Infantil necessita de orientação adequada para que a atividade escolar não seja entendida apenas como cumprimento de tarefa, sem que o desenvolvimento integral da criança seja assegurado. Mais do que propor atividades escolares, os cuidados com a saúde física e mental dos pequenos precisa ser considerada.

O Conselho Municipal de Educação poderia, com base em estudo técnico, propor alternativas mais viáveis para o atendimento da faixa etária e considerar a carga horária para compor as 800 horas necessárias para o cumprimento do ano letivo.

\section{Outras questões envolvidas na necessidade de estudo sobre a oferta de atividades escolares não presenciais}

O ensino não presencial é uma novidade para a maioria dos profissionais da Educação. Em que pese o Brasil ter investido em cursos de Graduação e Especialização na modalidade à distância, a oferta de algo semelhante para a Educação Básica não foi vivido de forma ampla na educação brasileira. Por isso há muitas incertezas, receios e preocupações.

Na proposta de deliberação, há questões não claras, tais como:

- A necessidade de formação continuada dos profissionais para a oferta de tais atividades, visto que não se trata apenas de transpor atividades presenciais para a forma não presencial. O ensino presencial é planejado a partir da interação professor-aluno, e, no ensino não presencial, essa interação não existe ou estará prejudicada;

- O controle de frequência estabelecido no art. $5^{\circ}$ precisa ser analisado com cuidado, principalmente por se tratar de atividades não presenciais;

- As metodologias utilizadas precisam ser pensadas a partir da realidade da comunidade escolar, visto que não há estudo sobre a disponibilidade de equipamentos (computadores, celulares, televisão, material impresso) para a utilização de estudantes, principalmente os mais vulneráveis;

- Como serão avaliadas as ações desenvolvidas para que se possibilite um redimensionamento caso necessário? Estão previstos fóruns virtuais ou outras medidas? (Citamos aqui o exemplo de Santa Maria (RS) que tem reunido virtualmente seus profissionais para tratar temas relevantes ao momento vivido). Destacamos a necessidade de pensarmos para além do ensino remoto - na importância de discussão e de preparo para o retorno, não apenas no sentido pedagógico, mas emocional e relacional.

- Quais as discussões acerca da avaliação da aprendizagem neste contexto de Pandemia?

\section{Considerações finais e declaração de voto}

Tendo em vista a situação social, política, econômica e, consequentemente, pedagógica vivida em razão da Pandemia causada pelo SARS-CoV-2, a tentativa de convencer os conselheiros 
sobre a necessidade de estudo sobre a realidade e a não aceitação de nossos argumentos pela maioria, só nos restou manifestação de VOTO CONTRÁRIO à aprovação da proposta.

Participamos do debate e não fomos convencidas pelos argumentos apresentados e não conseguimos convencer os demais conselheiros participantes da Reunião Extraordinária realizada em 19 de maio de 2020. Entretanto, reconhecemos que essa é uma forma, mesmo que limitada, de participação democrática.

Nossa história de luta por uma escola pública, justa, igual para todos, não nos permite outro posicionamento.

Colocamo-nos à disposição para debate posterior.

\section{Referências}

BRASIL. [Constituição (1988)]. Constituição da República Federativa do Brasil. Brasília, DF: Senado, 1988.

BRASIL. Lei $\mathbf{N}^{\circ}$ 9.394, de 20 de dezembro de 1996. Estabelece as diretrizes e bases da educação nacional. Brasília: Presidência da República, Casa Civil, Subchefia para Assuntos Jurídicos, [1996]. Disponível em: <http://www.planalto.gov.br/ccivil_03/leis/19394.htm>. Acesso em: 19 maio 2020.

NASCIMENTO, E.; MATIAS, L. F. Expansão urbana e desigualdade socioespacial: uma análise da cidade de Ponta Grossa (PR). RAEGA, v. 23. Curitiba, p. 65-97, 2011. Disponível em: <https://revistas.ufpr.br/raega/article/view/24833/16634>. Acesso em: 19 maio 2020.

PONTA GROSSA. Decreto Municipal no 17077, de 16 de março de 2020. Dispõe sobre a suspensão de atividades sujeitas à aglomeração de pessoas no âmbito do Município de Ponta Grossa, e dá outras providências. Diário Oficial do Município de Ponta Grossa. Edição no 2790, ano XII. 14, 15 e 16 de março de 2020 p. 4-5. Disponível em <http://www.pontagrossa.pr.gov.br/files/diario-oficial/2020-03-14-15-16.pdf>. Acesso em: 19 maio 2020. 